\title{
Metabolismo do ferro em equinos atletas
}

\author{
Iron metabolism in athletics horses \\ Luciana Pereira Machado $^{\mathrm{I} *}$ Aguemi Kohayagawa ${ }^{\mathrm{II}}$ Letícia Andreza Yonezawa
Veridiana Fernandes da Silveira'
}

- REVISÃO BIBLIOGRÁFICA -

\section{RESUMO}

O ferro participa de várias funções vitais do organismo, como o transporte de oxigênio e de elétrons e a síntese do DNA. Desequilíbrios do metabolismo do ferro podem estar relacionados a sua deficiência ou sobrecarga, porém a deficiência é rara em equinos adultos. Apesar disso, criadores e veterinários de cavalos de esporte utilizam frequentemente suplementos contendo ferro com o objetivo de melhorar o desempenho atlético. Até o momento, nenhum estudo comprovou que o exercício induz deficiência de ferro nessa espécie ou que a suplementação de ferro melhora o seu desempenho. O diagnóstico de deficiência ou sobrecarga de ferro depende de uma avaliação laboratorial criteriosa. A suplementação em equinos não deficientes pode induzir o acúmulo excessivo de ferro, com graves consequências para o animal. Este trabalho revisa as alterações do metabolismo do ferro em equinos submetidos ao exercício, os métodos laboratoriais de avaliação dos estoques de ferro e as consequências da suplementação indevida.

Palavras chave: ferro, cavalo, exercício, suplementação.

\section{ABSTRACT}

Iron participates in many vital functions, e.g. oxygen and electron transport, and DNA synthesis. Iron metabolism imbalances can be related to deficiency or overload;

\begin{abstract}
however, the deficiency is rare in adult horses. Despite this, breeders and veterinarians usually supplement horses with iron, aiming to improve athletic performance. Until now, no study proved that exercise induces iron deficiency in this species or that iron supplementation improves its performance. Diagnosis of iron deficiency or overload depends on a comprehensive laboratorial evaluation. Supplementation in horses without disabilities can induce excessive iron storage, with serious consequences for the animal. This study reviews the iron metabolism alterations in equine submitted to exercise, laboratorial methods for the evaluation of iron storage, and consequences of improper supplementation.
\end{abstract}

Key words: iron, horse, exercise, supplementation

\section{INTRODUÇÃO}

A maior parte do ferro presente no organismo apresenta-se ligado a proteínas, como os compostos heme, que são complexos de ferro e protoporfirina presentes na hemoglobina e mioglobina. A hemoglobina desempenha a função vital de transportar o oxigênio $\left(\mathrm{O}_{2}\right)$ para as células, e cada molécula de hemoglobina transporta até quatro

'Departamento de Medicina Veterinária, Universidade Federal do Piaú (UFPI), Campus Professora Cinobelina Elvas, Br 135, Km 3, 64900-000, Bom Jesus, PI, Brasil. E-mail: lup_machado@yahoo.com.br. *Autor para correspondência.

"Departamento de Clínica Veterinária, Faculdade de Medicina Veterinária e Zootecnia (FMVZ), Universidade Estadual Paulista (UNESP), Botucatu, SP, Brasil.

IIIPrograma de Pós-graduação em Medicina Veterinária, FMVZ, UNESP, Botucatu, SP, Brasil.

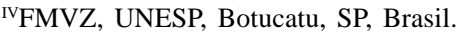

v'Departamento de Clinica e Patologia, Faculdade de Medicina Veterinária, Universidade do Estado de Santa Catarina (UDESC), Lages, SC, Brasil. 
moléculas de $\mathrm{O}_{2}$ (ALENCAR et al., 2002). Outras proteínas e enzimas, como citocromos, peroxidases, catalases, ribonucleotídeo redutase, aconitase e desidrogenase succínica também possuem ferro na sua constituição (SMITH, 1997; ALENCAR et al., 2002), sendo um elemento essencial para a síntese do DNA e o transporte de elétrons na respiração celular (DUNN et al., 2007).

O metabolismo do ferro depende da sua biodisponibilidade na dieta, da digestão e absorção intestinal, do transporte plasmático, da captação pelas células-alvo e dos mecanismos de estoque, reciclagem e excreção (ALENCAR et al., 2002). Na última década, foram identificadas novas proteínas envolvidas na captação do ferro pelos enterócitos e na sua liberação e no transporte intracelular; porém, muitas lacunas ainda existem quanto à atuação destas (ATANASIU et al., 2006; DUNN et al., 2007).

Desequilíbrios do metabolismo do ferro podem estar relacionados à deficiência ou sobrecarga, ambas altamente prejudiciais ao organismo. Nos equinos, a sobrecarga de ferro é mais frequente que a deficiência (LEWIS, 2000), a qual é considerada rara, ocorrendo principalmente em potros, pela baixa quantidade de ferro no leite (HARVEY et al., 1987). O alto teor de ferro nas forragens e grãos, aliado à capacidade desses animais de conservar o ferro, é suficiente para manter as necessidades de ferro (SMITH et al., 1986a). Na região do pantanal brasileiro, analisando estudos sobre a composição micromineral das gramíneas nativas e do solo, concluiu-se que não se deve incluir ferro nos suplementos minerais para equinos a pasto, visto que este está presente em quantidade excessiva nessas forragens (SANTOS, 1997). De modo geral, as forragens contêm de 50 a 400mg de ferro $\mathrm{kg}^{-1}$ de matéria seca, e os grãos de cereais, de 30 a $90 \mathrm{mg} \mathrm{kg}^{-1}$; já a necessidade de ferro para equinos adultos em mantença é de $40 \mathrm{mg}$ de ferro $\mathrm{kg}^{-1}$ de matéria seca (LEWIS, 2000).

A presença de processos inflamatórios pode induzir sequestro de ferro, condição na qual se observa hipoferremia, apesar do seu estoque estar adequado (SMITH et al., 1986a; BORGES et al., 2007). Esse fenômeno é denominado de pseudodeficiência de ferro. Nesses casos, a ferritina sérica apresenta-se normal, e a suplementação é contraindicada, pois poderia induzir sobrecarga do mineral (SMITH et al., 1986a). Além disso, a administração de ferro aumenta a susceptibilidade do animal a infecções bacterianas, mesmo em quantidades insuficientes para induzir toxicose (LEWIS, 2000). A redução do ferro plasmático pode ser utilizada como indicador de processo inflamatório em equinos (BORGES et al., 2007).
Em esportistas da espécie humana, a deficiência de ferro é uma condição frequente e está relacionada à diminuição do desempenho atlético (SCHUMACHER et al., 2002). Possivelmente influenciados por esses conceitos, criadores e veterinários de cavalos de esporte demonstram grande preocupação com a deficiência de ferro, evidenciada pela ampla utilização desses suplementos (SMITH et al., 1986a; SNOW \& HARRIS, 1989; HYYPPA et al., 2002). Em 1989, SNOW \& HARRIS já afirmavam que ferro é o mineral utilizado de maneira mais abusiva em equinos. A suplementação em equinos não deficientes induz o acúmulo excessivo de ferro no organismo (SMITH et al., 1986a; EDENS et al., 1993).

O interesse por estudos voltados para a medicina esportiva equina aumentou nas últimas décadas; contudo, alguns pontos ainda precisam ser elucidados. Até o momento, nenhum estudo comprovou que o exercício induz deficiência de ferro nessa espécie ou que a suplementação com ferro melhora o desempenho dos animais. O objetivo desta revisão é abordar as alterações do metabolismo do ferro em equinos submetidos ao exercício, os métodos laboratoriais de avaliação dos estoques de ferro e as consequências da suplementação indevida, de modo a fornecer subsídios para o melhor entendimento dos efeitos promovidos pelo exercício no metabolismo do ferro nos equinos e desestimular o uso indiscriminado de suplementos contendo ferro nesses animais.

\section{Metabolismo do ferro}

Na dieta, o ferro pode estar presente como ferro inorgânico ou na forma heme; a maior parte do ferro inorgânico apresenta-se no estado férrico $\left(\mathrm{Fe}^{3+}\right)$, que, para ser absorvido pelos enterócitos, precisa ser reduzido à forma ferrosa ( $\mathrm{Fe}^{2+}$ ) (ATANASIU et al., 2006). Essa reação ocorre na superfície apical dos enterócitos, sendo facilitada pela ação da enzima citocromo-b duodeno ferro redutase (DUNN et al., 2007). Esse $\mathrm{Fe}^{2+}$ penetra pela superfície apical dos enterócito, por canais de transportadores específicos, onde é novamente oxidado para a forma $\mathrm{Fe}^{3+}$ pela hefaestina, um homologo da ceruloplasmina (ATANASIU et al., 2006). A ceruloplasmina promove a oxidação do ferro e é responsável pela etapa final de absorção nos capilares da submucosa intestinal, facilitando a captação deste pela transferrina (ALENCAR, et al., 2002).

Na forma heme, o ferro é absorvido rapidamente, independente da composição da dieta, enquanto o ferro não heme é altamente indisponível e sua absorção é afetada pela dieta (ALENCAR et al., 2002). O consumo excessivo de cádmio, cobalto, cobre, manganês e zinco diminuem a absorção do ferro 
(LEWIS, 2000). Fitatos, oxalatos e fosfatos formam complexos com o ferro, retardando sua absorção (ALMEIDA et al., 2007). O conteúdo de ferro corporal também influencia a sua absorção intestinal, que aumenta com a perda de ferro e diminui quando há grandes estoques no organismo (ALENCAR et al., 2002).

A transferrina, proteína sintetizada nos hepatócitos e macrófagos, é responsável pelo transporte do ferro no plasma e nos líquidos extracelulares (ALENCAR et al., 2002). O ferro livre possui atividade oxido-redutora e promove a formação de radicais livres com grande potencial lesivo para os tecidos. A transferrina mantém o ferro em uma forma solúvel e não tóxica, evitando a formação dos radicais livres (PEELING et al., 2008). Além disso, a transferrina promove a entrada do ferro no interior das células (SMITH, 1997; PEELING et al., 2008). O ferro é estocado como ferritina e hemossiderina, com altas concentrações no fígado, no baço e na medula óssea. A ferritina garante uma reserva solúvel e difusa, constituindo um estoque mais prontamente disponível, e a hemossiderina apresenta maior teor de ferro, porém na forma de agregados insolúveis de baixa biodisponibilidade (SMITH, 1997).

Os estudos sobre o metabolismo do ferro progrediram muito nos últimos anos após a descoberta do peptídeo hepcidina, um hormônio produzido pelos hepatócitos que atua como o principal regulador do metabolismo do ferro (PEELING et al., 2008). O gene que codifica a sua expressão foi recentemente sequenciado em equinos (BORGES et al., 2008). Esse peptídeo bloqueia os canais de passagem de ferro na membrana celular dos enterócitos, hepatócitos e macrófagos. Como consequência, tem-se a inibição da absorção de ferro nos enterócitos e a sua retenção nos macrófagos e hepatócitos (PEELING et al., 2008).

A anemia representa um estímulo negativo para a síntese de hepcidina hepática, induzindo maior absorção de ferro pelos enterócitos e recirculação deste nos macrófagos, com maior aporte de ferro para a medula óssea e maior taxa de eritropoiese (ATANASIU et al., 2006). Por outro lado, os estímulos para síntese e liberação da hepcidina são o aumento dos estoques de ferro e os processos inflamatórios. A interleucina IL-6 estimula a produção de hepcidina que promove rápida redução de ferro sanguíneo, estabelecendo um obstáculo à síntese de hemoglobina que pode resultar em anemia (PEELING et al., 2008). Os precursores eritroides são as células que possuem maior exigência de ferro para a síntese da hemoglobina (SMITH, 1997). O organismo consegue suprir a maior parte da demanda de ferro para a eritropoiese pela reciclagem do ferro presente nos eritrócitos. A reciclagem é realizada pelos macrófagos que fagocitam os eritrócitos velhos e reaproveitam o ferro da hemoglobina; este mecanismo é mais importante que a aquisição de ferro pela dieta (DUNN et al., 2007).

Os equinos não possuem mecanismos ativos de excreção de ferro (LEWIS, 2000). Ocorrem mínimas perdas diárias principalmente pelas fezes, proveniente da descamação de células da mucosa intestinal e do ferro biliar não absorvido, o restante é perdido pela descamação cutânea e excreção urinária em concentrações muito baixas (ALENCAR et al., 2002). Essa pequena perda diária é compensada pela absorção intestinal, mantendo em equilíbrio o teor de ferro do organismo (DUNN et al., 2007).

Métodos laboratoriais para avaliação do metabolismo do ferro

As alterações do metabolismo do ferro podem ser avaliadas por várias provas laboratoriais. Os testes hematológicos, a determinação sérica do ferro, da capacidade total da ligação do ferro, do índice de saturação da transferrina e da concentração de ferritina e a avaliação do conteúdo medular de ferro são os mais utilizados (ALENCAR et al., 2002).

A mensuração de variáveis eritrocitárias, como o hematócrito e a concentração de hemoglobina, é comumente utilizada para avaliar se o status de ferro está adequado nos equinos, apesar de não constituírem indicadores confiáveis para esse fim. Anemia não é sinônimo de deficiência de ferro, e a síntese de hemoglobina tem preferência em relação a outras proteínas constituídas por ferro, ocorrendo diminuição da síntese de hemoglobina apenas nas deficiências severas (SMITH et al., 1986a). Apesar de isolados não terem valor diagnóstico para os teores de ferro, a realização do eritrograma completo deve fazer parte da avaliação do metabolismo do ferro. As variáveis eritrocitárias estão geralmente normais durante os estágios iniciais da deficiência de ferro, enquanto a deficiência crônica é caracterizada por anemia microcítica hipocrômica (HARVEY, 2000).

O compartimento de transporte pode ser avaliado pela concentração sérica de ferro e por índices que avaliam indiretamente a concentração de transferrina, por meio de técnicas colorimétricas simples, já a mensuração da transferrina total é pouco utilizada. Quando a transferrina é saturada com uma concentração conhecida de ferro, a quantidade total desse mineral ligado a ela é chamada de capacidade total de ligação do ferro (CTLF). Como a transferrina sérica normalmente não se encontra saturada, a CTLF é maior do que a concentração de ferro sérica, sendo a 
diferença entre eles denominada capacidade latente de ligação do ferro (CLLF). O índice de saturação da transferrina (IST) refere-se à porcentagem que está na forma ligada ao ferro, obtida pela divisão da concentração de ferro pela CTLF (SMITH, 1997; ALENCAR et al., 2002). Observa-se ampla faixa de variação entre equinos normais para o ferro sérico, CTLF, CLLF e IST(SMITH et al., 1986a; FERNANDES et al., 1999; ABRAMOVITC et al., 2008). LEWIS (2000) analisou os resultados de vários trabalhos e sugere como valores de referência para equinos 120 a $210 \mu \mathrm{g}$ $\mathrm{dL}^{-1}$ para o ferro sérico; 370 a $470 \mu \mathrm{g} \mathrm{dL} \mathrm{d}^{-1}$ para a CTLF; 200 a $300 \mu \mathrm{g} \mathrm{dL} \mathrm{dL}^{-1}$ para CLLF e 30 a $50 \%$ para o IST.

A concentração de ferro sérica não reflete os estoques do organismo (HARVEY et al., 1987). Um bom índice para a avaliação desse estoque é a dosagem da ferritina sérica, que possui forte correlação com o conteúdo de ferro hepático e esplênico (SMITH et al., 1984; HYYPPA et al., 2002). SMITH et al. (1984) desenvolveram um ensaio imuno enzimático (ELISA) para a determinação da ferritina sérica equina, obtendo valores de 66 a $305 \mu \mathrm{g} \mathrm{L}^{-1}$ em 28 equinos normais. LEWIS (2000) sugere que valores de ferritina de 30 a $250 \mu \mathrm{g} \mathrm{L}^{-1}$ indicam estoque de ferro adequado, resultados inferiores deficiência e superiores sobrecarga. HYYPPA et al. (2002) observaram resultados basais de ferritina inferiores, com valores abaixo de $20 \mu \mathrm{g} \mathrm{L}^{-1}$, porém foi avaliada a concentração de ferritina plasmática. A ferritina plasmática é $24 \%$ menor em média que a ferritina sérica (ORINO et al., 1993).

A imunoturbidometria foi inicialmente utilizada na medicina veterinária para a determinação da ferritina sérica em suínos (ALMEIDA, et al., 2007). Recentemente a técnica foi utilizada para a determinação da ferritina sérica em 16 equinos da raça Árabe, e foram observados valores basais de ferritina de 24 a 234,6 $\mu \mathrm{g} \mathrm{L}^{-1}$, pois trata-se de um método mais prático e acessível e que demonstrou resultados semelhantes aos observados nos estudos anteriores com método de ELISA (MACHADO, 2009).

A diminuição da ferritina é um indicativo confiável de deficiência de ferro, porém resultados normais e elevados devem ser avaliados com cautela. Outros fatores, além do acúmulo de ferro, promovem aumento de ferritina, podendo ocasionar resultados falsamente elevados ou mascarar uma deficiência. A ferritina é uma proteína de fase aguda que aumenta em resposta à inflamação, a infecções, a hepatopatias, a neoplasias e ao exercício (SCHUMACHER et al., 2002). Deve ser instituído um período mínimo de dois dias sem realização de atividade física intensa para a avaliação de estoques de ferro por meio da ferritina (HYYPPA et al., 2002).
Uma alternativa à determinação da ferritina é a dosagem sérica do receptor solúvel de transferrina (sTfr), utilizada em humanos por kits de nefelometria, principalmente na suspeita de deficiência de ferro associada a doenças infecciosas e/ou inflamatórias ou para diferenciar deficiência de sequestro de ferro. A concentração de sTfr aumenta na deficiência de ferro e não sofre influência de processos inflamatórios, porém ela também eleva-se em resposta ao aumento da eritropoiese (SCHUMACHER et al., 2002). Ainda não existem relatos da utilização do sTfr em medicina equina. A haptoglobina plasmática pode ser associada à avaliação do metabolismo do ferro em equinos atletas, por ser um indicador de hemólise intravascular durante o exercício, porém por ser uma proteína de fase aguda também aumenta nos processos inflamatórios (HANZAWA et al., 2002). A haptoglobina plasmática pode ser mensurada por imunodifusão radial, pois por essa técnica obteve-se concentração média de $942 \pm 218 \mathrm{mg} \mathrm{mL}^{-1}$ em quatro equinos em repouso (INOUE et al., 2005).

O ferro tecidual pode ser avaliado por biópsia ou punção aspirativa de fígado ou medula óssea; já a avaliação do ferro medular pode ser realizada por método histoquímico com corante Azul-da-Prússia, o qual tem bom valor diagnóstico para a deficiência e para a diferenciação entre deficiência e pseudodeficiência de ferro, ocorrendo depleção dos estoques medulares na deficiência, enquanto que na pseudo-deficiência o ferro medular apresenta-se de normal a aumentado (SMITH, 1997; ALENCAR et al., 2002). A determinação química da concentração de ferro hepático é mais aplicada para o diagnóstico da sobrecarga (WORWOOD, 1997).

\section{Ferro e exercício físico}

O exercício intenso e regular promove aumento da síntese de mioglobina e enzimas que contêm ferro, o qual, associado à elevação da taxa de eritropoiese e às perdas pelo trato digestório, urinário e suor, aumenta a demanda de ferro do organismo. Em humanos, a dieta geralmente não consegue suprir o aumento da exigência, acarretando deficiência desse mineral (SZYGULA, 1990). INOUE et al. (2005) avaliaram as perdas de ferro pelo suor e pela urina em equinos submetidos a exercícios de diferentes intensidades, não observando aumento das perdas em nenhum tipo de exercício. A deficiência de ferro aparece como a desordem de microminerais mais conhecida em esportistas da espécie humana, tendo importância por causar anemia e diminuir o desempenho atlético (SCHUMACHER et al., 2002). 
A deficiência de ferro pode ser dividida em três categorias, segundo o estágio de severidade: o primeiro é caracterizado por depleção dos estoques de ferro na medula óssea, no baço e no fígado; no segundo estágio, já ocorre uma diminuição da eritropoiese ainda sem anemia; e o terceiro estágio corresponde à clássica anemia por deficiência de ferro (SMITH, 1997; PEELING et al., 2008). A redução do desempenho atlético é documentada em atletas da espécie humana, principalmente nas categorias mais graves de deficiência de ferro, nas quais a diminuição do aporte de $\mathrm{O}_{2}$ aos músculos, devido à anemia, justifica o pior rendimento. Ainda são necessários mais estudos para esclarecer o real efeito da deficiência de ferro sem anemia no desempenho atlético (PEELING, et al., 2008).

Nos equinos, especula-se que as exigências de ferro também aumentem com o exercício físico, porém algumas particularidades da espécie evitam a deficiência (LEWIS, 2000). As reservas de ferro depositadas no fígado, no baço e na medula óssea são bem maiores nos equinos quando comparados aos humanos (FRANKEN et al., 1981). Além disso, o exercício aumenta a exigência energética dietética, induzindo maior consumo de alimento e consequentemente de ferro (LEWIS, 2000). Apesar de desconhecer o mecanismo exato, INOUE et al. (2005) sugerem que os equinos possam ainda aumentar a absorção de ferro para compensar a maior demanda induzida pelo exercício.

MILLS e colaboradores (1996) submeteram equinos ao exercício em esteira simulando, tanto uma prova de corrida de alta velocidade, como o exercício de enduro. Na simulação do enduro, observaram aumento discreto do ferro plasmático nas primeiras 24 horas pós-exercício (dois min, cinco min, 12h e 24h) associado a aumento da saturação de transferrina, atribuindo esse aumento a uma mobilização de ferro estocado para a medula, possivelmente para suprir uma elevação na taxa de eritropoiese.

O ferro sérico pode elevar-se após o exercício por diferentes mecanismos: o aumento do ferro sérico e da saturação da transferrina reflete a sua mobilização do sistema reticuloendotelial para a medula óssea (MILLS et al., 1996); logo após o exercício de curto período e alta intensidade em esteira, o aumento de ferro sérico sem alteração do IST indica falso aumento, em razão da hemoconcentração (MACHADO, 2009). O cortisol também exerce efeito na concentração sérica de ferro, porém mais tardio, já a administração exógena de corticóides, em equinos e pôneis, aumenta a concentração de ferro 48 a $72 \mathrm{~h}$ após o tratamento, sem alterações da CTLF e da ferritina (SMITH et al., 1986b). O aumento de cortisol endógeno, induzido pelo exercício de curto período e pela alta intensidade em esteira, foi relacionado à elevação do ferro sérico $72 \mathrm{~h}$ após o exercício em equinos (MACHADO, 2009).

Em atletas da espécie humana, relata-se a presença da chamada "anemia do esporte”, podendo ser uma anemia verdadeira devido à deficiência de ferro ou hemólise, ou uma falsa anemia, "pseudoanemia”, causada pela diluição dos eritrócitos resultante do aumento do volume plasmático induzido pelo exercício aeróbico (SCHUMACHER et al., 2002; MARTINEZ et al., 2006). A “anemia do esporte” já foi sugerida em equinos em razão da hemólise induzida pelo exercício (MASINI et al., 2003) ou do aumento do volume plasmático como resposta fisiológica ao treinamento de enduro (MCKEEVER et al., 1987) e ao exercício em esteira da alta intensidade e curta duração (MACHADO, 2009). Porém, nenhum estudo comprovou que o exercício promove deficiência de ferro em equinos (INOUE et al., 2005).

Redução do ferro sérico pode estar relacionada à pseudodeficiência de ferro, que ocorre como uma resposta de fase aguda e representa a alteração do metabolismo do ferro mais frequente em equinos (SMITH et al., 1986a). A resposta inflamatória induz sequestro de ferro como um mecanismo de defesa do organismo à infecção, pois a maioria dos microorganismos necessita do ferro para seu desenvolvimento (SMITH, 1997; LEWIS, 2000). Nas primeiras 24 horas, ocorre rápida e intensa hipoferremia associada ao aumento na síntese de proteínas de fase aguda, como a ferritina, haptoglobina e ceruloplasmina (SMITH, 1997).

Os efeitos do exercício no metabolismo do ferro ocorrem como reações de fase aguda semelhantes às observadas na resposta inflamatória (SCHUMACHER et al., 2002). A hepcidina é responsável pelo sequestro do ferro, e em atletas da espécie humana foi observado que o tipo, a intensidade e a duração do exercício influenciam a magnitude do aumento de hepcidina (PEELING et al., 2008). Em equinos, ainda não foi avaliado o efeito do exercício na síntese de hepcidina, porém acredita-se que este seja o mecanismo responsável pela redução do ferro sérico após o exercício (MACHADO, 2009).

A síntese de ferritina aumenta como resposta de fase aguda; além disso, no exercício, ocorrem lesões nas membranas celulares em órgãos responsáveis pelo estoque de ferro, como o fígado, causando liberação de ferritina tecidual para a circulação. Alterações hemodinâmicas, como a hemoconcentração e o aumento do volume plasmático, também influenciam as concentrações séricas de ferritina (SCHUMACHER et al., 2002). 
Em equinos que realizaram uma prova de corrida de curto período e moderada intensidade, a ferritina aumentou logo após o exercício e retornou aos valores basais em seis horas. Em outra prova de competição de trote classificada como exercício máximo, a ferritina foi avaliada apenas $24 \mathrm{~h}$ após o exercício e apresentou-se elevada. Os pesquisadores concluíram que um único episódio de exercício induz aumento transitório de ferritina, tendo relação direta com a intensidade e duração do exercício (HYYPPA et al., 2002).

Equinos das raças Árabe e meio-sangue Árabe submetidos a uma prova de enduro de regularidade, de baixa intensidade, não apresentaram alterações do ferro sérico ou do IST, ocorrendo apenas aumento da CTLF. Porém, os valores da CTLF foram muito superiores aos observados na literatura, possivelmente devido às condições de armazenamento da amostra. Os autores concluíram que o exercício realizado foi muito leve para induzir alterações no metabolismo do ferro (FERNANDES et al., 1999). Em outro estudo, 112 equinos da raça Puro Sangue Inglês realizaram uma prova de exercício ao galope, de alta intensidade e curta duração, observando-se redução significativa do ferro sérico e do IST associado à diminuição da CTLF 30 minutos após o exercício (ABRAMOVITC et al., 2008).

Os resultados desses dois estudos citados reforçam o conceito de que a magnitude do sequestro de ferro induzido por reação de fase aguda pós-exercício provavelmente seja influenciada pela intensidade do exercício (INOUE et al., 2005; PEELING et al., 2008). Além disso, em ambos os estudos, as análises foram procedidas apenas antes e 30 minutos após o exercício. Mais momentos deveriam ter sido avaliados nas primeiras 24 horas, pois, segundo PEELING et al. (2008), o pico de hepcidina ocorre seis horas após o estímulo inflamatório. Uma avaliação mais adequada deve contemplar o período de seis a 24 horas pós-exercício. Equinos que realizaram uma prova de enduro de $140 \mathrm{~km}$ em 8,5 horas, considerada de baixa a média intensidade, apresentaram redução do ferro sérico imediatamente após o exercício (MARLIN et al., 2002). Nesse caso, provavelmente, o longo período da prova foi suficiente para ocorrer aumento de hepcidina, justificando a redução do ferro logo após o exercício.

Durante o exercício, os eritrócitos são submetidos a estresse físico e químico, promovendo aumento da fragilidade da membrana eritrocitária e hemólise (HANZAWA et al., 2002). Essa hemólise intravascular pode ser confirmada pelo aumento da hemoglobina livre e da concentração de haptoglobina sérica, após o exercício em equinos (HANZAWA et al., 2002; MASINI et al., 2003). Em equinos submetidos ao exercício em esteira, que simularam, tanto provas de corrida de alta velocidade, como exercício de enduro, não se observou presença de ferro livre (MILLS et al., 1996).

No entanto, a maior destruição eritrocitária não aumenta a exigência de ferro, pois o ferro é reutilizado na produção de novos eritrócitos (LEWIS, 2000). A haptoglobina se liga à hemoglobina livre e a destina para a fagocitose e reciclagem, evitando perdas excessivas de ferro (HANZAWA et al., 2002). A hemólise poderá induzir anemia se estiver associada ao aumento de IL-6, que provoca retenção, nos macrófagos, do ferro proveniente da fagocitose dos eritrócitos, comprometendo a eritropoiese (PEELING et al., 2008). Segundo MASINI et al. (2003), equinos sob longos períodos de treinamento acumulam ferro no fígado e diminuem os estoques na medula óssea, limitando a sua biodisponibilidade para a eritropoiese e podendo ocasionar anemia verdadeira e comprometer o desempenho dos equinos.

Sobrecarga de ferro por uso inadequado de suplementos

A administração de suplementos de ferro com o objetivo de melhorar o desempenho atlético é uma prática frequente. Contudo, a suplementação só melhora o desempenho se houver deficiência; a administração extra de ferro não trará nenhum incremento ao desempenho do animal quando não existir deficiência, podendo ser prejudicial. A toxicose por ferro é muito mais comum nos equinos que a sua deficiência (LEWIS, 2000). Um suplemento comumente utilizado nos equinos são os hematínicos, compostos utilizados com o objetivo de aumentar o número de eritrócitos. Potros da raça Crioula de 24 meses receberam um hematínico oral composto por ferro, zinco, ácido fólico e vitaminas do complexo B por 60 dias. A suplementação não promoveu alteração das variáveis hematológicas, comprovando que esses suplementos não possuem efeito em animais não deficientes. Os animais não apresentaram sinais clínicos de toxicose por ferro (RIBEIRO, 2005). Porém, não foi mensurada nenhuma variável específica do metabolismo do ferro para excluir uma possível sobrecarga de ferro.

Quando se avaliou o status de ferro em 100 equinos hospitalizados, $10 \%$ dos animais apresentaram sobrecarga de ferro. A concentração sérica de ferro permaneceu dentro dos valores de normalidade; contudo, a ferritina sérica estava fortemente elevada. Segundo os autores, o excesso de ferro nesses animais teve causa iatrogênica (SMITH et al., 1986a). Como não há um mecanismo fisiológico efetivo que aumente 
a excreção do ferro, todo o excesso é estocado nos tecidos, induzindo lipoperoxidação e disfunção de organelas, tal como a destruição de mitocôndrias mediada por radicais livres (PEARSON \& ANDREASEN, 2001).

A intoxicação por ferro representa um quadro de sobrecarga com manifestações clínicas graves, como as hepatopatias (EDENS et al., 1993; PEARSON \& ANDREASEN, 2001). Vários fatores influenciam o desenvolvimento de toxicose, como a forma de administração do ferro. Na forma injetável, há maior probabilidade de toxicose do que por via oral (LEWIS, 2000). O ferro, quando injetado, pode ultrapassar a capacidade de ligação da transferrina, levando a acúmulo de ferro livre (PEARSON \& ANDREASEN, 2001). O ferro livre possui efeito pró-oxidante, induzindo a formação de radicais livres e a transformação de substâncias oxidantes em formas mais reativas. $\mathrm{O} \mathrm{H}_{2} \mathrm{O}_{2}$, na presença do ferro, produz o radical livre $\mathrm{OH}^{2}{ }^{-{ }^{\prime}}$, altamente deletério, sendo mais prejudicial em animais de esporte, pela maior produção de radicais livres durante o exercício (KIRSCHVINK et al., 2008).

O ferro como sulfato ferroso é mais facilmente absorvido por via oral que o ferro férrico, tendo alto potencial de intoxicação (PEARSON \& ANDREASEN, 2001). EDENS et al. (1993) relatam o caso de um equino que recebeu suplemento oral à base de sulfato ferroso, $0,6 \mathrm{mg}$ de ferro $\mathrm{kg}^{-1} \mathrm{dia}^{-1}$, por seis semanas, desenvolvendo quadro grave de intoxicação com hepatopatia, linfopenia, trombocitopenia, intensa hiperferremia (457mg mL $\mathrm{m}^{-1}$ ) e elevação da CTLF. Em outro estudo, 50mg de ferro $\mathrm{kg}^{-1} /$ dia na forma de sulfato ferroso foram adicionados à alimentação de pôneis por oito semanas, promovendo sobrecarga de ferro, com aumento da concentração de ferro sérico e hepático, da ferritina e do IST. Porém, não foi observada evidência clínica ou histológica compatível com intoxicação. Os autores acreditam que os quadros de intoxicação observados em estudos anteriores com concentrações menores de ferro estavam relacionados à hepatopatia pré-existente (PEARSON \& ANDREASEN, 2001).

Não se sabe ainda qual a quantidade de ferro necessária para desencadear intoxicação, sendo influenciada por outros fatores, como a forma de administração do ferro, as doenças concomitantes e a concentração de antioxidantes, principalmente vitamina E e selênio (EDENS et al., 1993). Uma observação comum em estudos com suplementação excessiva de ferro é o longo período necessário para a normalização dos estoques de ferro após a retirada do suplemento, superior a quatro meses, ressaltando a dificuldade do organismo em eliminar o ferro excedente (EDENS et al., 1993; PEARSON \& ANDREASEN, 2001).

\section{CONCLUSÃO}

Conclui-se que o exercício pode induzir diferentes alterações no metabolismo do ferro, dependendo da intensidade e duração, sendo o sequestro de ferro o evento mais comum. A avaliação do metabolismo do ferro não deve ser realizada por um único índice laboratorial e exige interpretação cautelosa dos resultados. As análises, com objetivo de verificar os efeitos do exercício no metabolismo do ferro, devem contemplar principalmente o período entre seis e 24 horas pós-exercício, excluindo-se o efeito imediato da hemoconcentração. Para determinar os estoques de ferro pela dosagem da ferritina sérica, deve-se respeitar um período mínimo de dois dias sem exercício. Sabendose que a deficiência de ferro é rara e que a sobrecarga desse mineral pode causar sérios prejuízos, a utilização de suplementos contendo ferro em animais não deficientes é desaconselhável. Há muito para ser estudado quanto aos efeitos do exercício no metabolismo do ferro, principalmente quanto a sua relação com a resposta inflamatória.

\section{REFERÊNCIAS}

ABRAMOVITC, G. et al. Influência do exercício físico sobre os níveis de ferro, da capacidade total de ligação do ferro e da saturação da transferrina em equinos de corrida. In: CONGRESSO INTERNACIONAL DE MEDICINA EQUINA, 4., 2008, São Paulo. Anais... São Paulo: Associação Brasileira dos Veterinários de Equinos, 2008. np.

ALENCAR, N.X. et al. Metabolismo do ferro nos animais domésticos: revisão. Revista de Educação Continuada do CRMV/SP, v.5, p.192-205, 2002.

ALMEIDA, R.F. et al. Metabolismo do ferro em suínos recebendo dietas contendo fitase, níveis reduzidos de fósforo inorgânico e sem suplemento micromineral e vitamínico. Ciência Rural, v.37, p.1097-1103, 2007. Disponível em: <http://www.scielo.br/pdf/cr/v37n4/a29v37n4.pdf> Acesso em: 25 out. 2009. doi: 10.1590/S0103-84782007000400029.

ATANASIU, V. et al. Hepcidin - central regulador of iron metabolism. European Journal of Haematology, v.78, p.110, 2006. Disponível em: <http://dx.doi.org/10.1111/j.16000609.2006.00772.x>. Acesso em: 25 out. 2009. doi: 10.1111/ j.1600-0609.2006.00772.x

BORGES, A.S. et al. "Equine hepcidin: mRNA sequence and expression in liver tissue”. In: INTERNATIONAL CONGRESS OF THE WORLD EQUINE VETERINARY ASSOCIATION, 10., 2008, Moscow. Proceedings... Moscow: World equine veterinary association, 2008. p.612.

BORGES, A.S. et al. Serum iron and plasma fibrinogen concentration as indicators of systemic inflammatory diseases in horses. Journal of Veterinary Internal Medicine, v.21, p.489-494, 2007. 
DUNN, L.L. et al. Iron uptake and metabolism in the new millennium. Trends in Cell Biology, v.17, p.93-100, 2007. Disponível em: <http://dx.doi.org/ oi:10.1016/j.tcb.2006.12.003>. Acesso em: 25 out. 2009. doi:10.1016/j.tcb.2006.12.003.

EDENS, L.M. et al. Cholestatic hepatopathy, thrombocytopenia and lymphopenia associated with iron toxicity in a thoroughbred gelding. Equine Veterinary Journal, v.25, p.81-84, 1993.

FERNANDES, W.R. et al. Influência do exercício físico sobre os níveis séricos de ferro e de capacidade total de ligação do ferro em equinos de enduro. Veterinária Notícias, v.5, p.7982, 1999.

FRANKEN, P. et al. The concentration of iron in the liver, spleen and plasma, and the amount of iron in bone marrow of horses. Zentralblatt für Veterinärmedizin, v.28, p.381389, 1981.

HANZAWA, K. et al. Effects of exercise on plasma haptoglobin composition in control and splenectomized Thoroughbred horses. Journal of Equine Science, v.13, n.3, p.89-92, 2002. Disponível em: < http://www.jstage.jst.go.jp/article/jes/13/3/ 13_89/_article/-char/en>. Acesso em: 25 out. 2009. doi: $10.1294 /$ jes.13.89.

HARVEY, J.W. Erythrocyte metabolism. In:_ FELDMAN, B.F. et al. Schalm's veterinary hematology. 6.ed. Philadelphia: Lippincott Williams \& Wilkins, 2000. p.125128.

HARVEY, J.W. et al. Serum ferritin, serum iron, and erythrocyte value in foals. American Journal of Veterinary Research, v.48, p.1348-1352, 1987.

HYYPPA, S. et al. Effect of exercise on plasma ferritin concentrations: implication for the measurement of iron status. Equine Veterinary Journal, supl.34, p.186-190, 2002.

INOUE, Y. et al. Effect of exercise on iron metabolism in horses. Biological Trace Element Research, v.107, p.3342, 2005.

KIRSCHVINK, N. et al. The oxidant/antioxidant equilibrium in horses. Veterinary Journal, v.177, p.178-191, 2008. Disponível em: <http://dx.doi.org/ 10.1016/j.tvjl.2007.07.033>. Acesso em: 25 out. 2009. doi: 10.1016/j.tvjl.2007.07.033.

LEWIS, L.D. Minerais para os equinos. In_ LEWIS, L.D._ Nutrição clínica equina - alimentação e cuidados. São Paulo: Roca, 2000. Cap.2, p.29-73.

MACHADO, L.P. Metabolismo do ferro e lipoperoxidação eritrocitária em equinos Puro Sangue Árabe submetidos ao exercício em esteira e suplementados com vitamina E (dl-alfa-tocoferol). 2009. 71f. Tese (Doutorado em Clinica Veterinária) - Faculdade de Medicina Veterinária e Zootecnia, Campus de Botucatu, Universidade Estadual Paulista, SP.

MARLIN, D.J. et al. Changes in circulatory antioxidant status in horses during prolonged exercise. Journal of Nutrition, v.132, p.1622S-1627S, 2002. Disponível em: < http:// jn.nutrition.org/cgi/reprint/132/6/1622S> Acesso em: 25 out. 2009.
MARTINEZ, A.C. et al. Hand strike-induced hemolysis and adaptations in iron metabolism in Basque ball players. Annals of Nutrition and Metabolism, v.50, p.206-213, 2006. Disponível em: <http://dx.doi.org/10.1159/000090742>. Acesso em: 25 out. 2009. doi: 10.1159/000090742.

MASINI, A.P. et al. Exercise-induced intravascular haemolysis in standarbred horses. Comparative Clinical Pathology, v.12, p.45-48, 2003. Disponível em: <http://dx.doi.org/ 10.1007/s00580-002-0470-y>. Acesso em: 25 out. 2009. doi: 10.1007/s00580-002-0470-y.

MCKEEVER, K.H. et al. Exercise training-induced hypervolemia in the horse. Medicine and Science in Sports and Exercise, v.19, p.21-27, 1987.

MILLS, P.C. et al. Effects of exercise intensity and environmental stress on indices of oxidative stress and iron homeostasis during exercise in the horse. European Journal of Applied Physiology, v.74, p.60-66, 1996. Disponível em: <http://dx.doi.org/ 10.1007/BF00376495>. Acesso em: 25 out. 2009. doi: 10.1007/BF00376495.

ORINO, R. et al. Fibrinogen as a ferritin-binding protein in horse plasma. Journal of Veterinary Medical Science, v.55, p.785-787, 1993.

PEARSON, G.E.; ANDREASEN, C.B. Effect of oral administration of excessive iron in adult ponies. Journal of the American Veterinary Medicine Association, v.218, p.400-404, 2001. Disponível em: <http://dx.doi.org/ 10.2460/ javma.2001.218.400>. Acesso em: 25 out. 2009. doi: 10.2460/ javma.2001.218.400.

PEELING, P. et al. Athletic induced iron deficiency: new insights into the role of inflammation, cytokines and hormones. European Journal of Applied Physiology, v.103, p.381391, 2008. Disponível em: <http://dx.doi.org/ 10.1007/s00421008-0726-6>. Acesso em: 25 out. 2009. doi: 10.1007/s00421008-0726-6.

RIBEIRO, M.D. Parâmetros hematológicos de potros da raça Crioula suplementados com um hematínico. 2005. 52f. Dissertação (Mestrado em Clínica Veterinária) Universidade Federal de Santa Maria, Santa Maria, RS.

SANTOS, S.A. Recomendações sobre manejo nutricional para equinos criados em pastagens nativas no Pantanal. Corumbá: EMBRAPA - CPAP, 1997. 63p.

SCHUMACHER, Y.O. et al. Effects of exercise on soluble transferring receptor and other variables of the iron status. British Journal of Sports Medicine, v.36, p.195-200, 2002. Disponível em: < http://bjsportmed.com/cgi/content/abstract/ 36/3/195>. Acesso em: 25 out. 2009. doi: 10.1136/ bjsm.36.3.195.

SMITH, J.E. Iron metabolism and its disorders. In: KANEKO, J.J. et al. Clinical biochemistry of domestic animals. San Diego: Academic, 1997. Cap.97, p.223-239.

SMITH, J.E et al. Iron deficiency and pseudo-iron deficiency in hospitalized horses. Journal of the American Veterinary Medical Association, Schaumburg, v.188, p.285-287, 1986a. 
SMITH, J.E. et al. Exogenous corticosteroids increase serum iron concentration in mature horses and ponies. Journal of the American Veterinary Medical Association, v.188, p.1296-1298, 1986b.

SMITH, J.E. et al. Serum ferritin as a measure of stored iron in horses. Journal of Nutrition, v.114, p.677-681, 1984.

SNOW, D.H.; HARRIS, R.C. The use of conventional and unconventional supplements in the thoroughbred horse. Proceedings Nutrition Society, v.48, p.135-139, 1989.
SZYGULA, Z. Erythrocytic system under the influence of physical exercise and training. Sports Medicine, v.10, p.181197, 1990.

WORWOOD, M. The laboratory assessment of iron status an update. Clinica Chimica Acta, v.259, p.3-23, 1997. Disponível em: <http://dx.doi.org/ 10.1016/S00098981(96)06488-1>. Acesso em: 25 out. 2009. doi: 10.1016/ S0009-8981(96)06488-1. 